and never healed up, though the margin of it may cicatrize, and you are left to your ingenuity to fill the gap by a plate of silver, gutta-percha, or other contrivance.

The metacarpal and metatarsal bones, and the phalanges, are liable to this chronic scrofulous ulceration, the metatarsal bone of the great toe more than any other. There are at the present time in the hospital three young persons with this disease. In one it affects the proximal, and in the other the distal, end of the bone. It commenced with swelling, as if there were synovial disease of the neighbouring joints, but I cannot be sure whether this were really the case, or whether the inflammation commenced in the extremities of the bones themselves. Soon matter formed, and was discharged, leaving sinuses, which lead down to the carious surfaces. Some fragments of bone have been discharged. It may be that removal of some portion will be required, but this is not often necessary, for if the health of the patients be improved, the disease will probably cease, the ulcerated surfaces will heal over, or the adjacent ends become anchylosed, and the toes will be somewhat shortened, in consequence of the loss of some of the bony substance, which will be re-produced only to a very slight extent.

It was long suppposed that the common scrofulous disease of the joints commences with inflammation and deposit into the cancellous substance of the bones; the synovial affection being thought to be secondary to this. Recent and more accurate pathological investigation has proved this view to be by no means correct. In the cases where joints have been examined during the early stage of scrofulous disease, the bones have generally been sound, and the synovial membrane the only part presenting the signs of inflammation. The symptoms also accord best with this view, for the swelling, which appears at an early period, and is often the first sign of disease, takes the direction of the synovial membrane, and seems to depend either upon thickening of it, or effusion into its cavity. The cartilages disappear in young subjects without much pain, and the work of destruction is propagated to, and goes on with, great comparative rapidity in the loose friable structure of the articular extremities of the bones. Now and then, no doubt, the order of the progress of the disease is reversed: it may commence with inflammation of the cancellous extremities of the bones, and extend from them to the synovial membrane and the cartilages, but in the greater number of cases the synovial membrane is the part first affected.

I have no particular remarks to make with regard to the treatment of this disease of the bones, in addition to those which I have specified when speaking of the general management of scrofulous patients. The inflammation certainly is not more easily subdued when it attacks the bones, than when it appears in the softer structures of the body; and I am not aware that any benefit is to be expected from local applications. I am in the habit of allowing the patients to go out of doors, even at the risk of some detriment to the part affected. I think in the early stages of the disease, when the symptoms of inflammation only are present, that a few leeches may be applied, and repeated at short intervals, with advantage. You will remember that this local depletion is by no means incompatible with a general tonic regimen. When suppuration has taken place, the importance of endeavouring to promote the absorption of the pus is increased by the difficulty with which the cure of a sinus conneeted with an ulcerated bone is accomplished; and I have before told you, that the absorption of pus lying upon a diseased bone is more likely to take place than under other circumstances. We have, therefore, the double reason for persevering with those applications which seem to assist in promoting this desirable end, such as the tincture of iodine painted once or twice a-day upon the skin, so as to keep up a free scaling of the cuticle, or a succession of small blisters in the immediate neighbourhood of the abscess.

The only instance in which I am aware that scrofulous inflammation affects the cartilages, is in the larynx, where they suffer both primarily, and as a consequence of disease, of the mucous membrane. In this specimen the cricoid cartilage is necrosed, separated from the adjacent tissues, and bathed in thick curdy pus. The patient died in consequence of the swollen state of the mucous membrane and submucous tissue closing the opening of the glottis. Here are also specimens of the same disease in the thyroid as well as the cricoid cartilage, and it is in like manner attended with the formation of abscess and with inflammation of the mucous membrane of the larynx. The disease you see is in each instance confined to the larynx, and does not extend to the trachea, so that the operation of tracheotomy, performed in the usual situation, would be fairly below the seat of the mischief; this would not be quite so certain if laryngotomy, or the incision between the cartilages of the larynx, were resorted to. These cases, however, are generally complicated with so much disease in the lungs and other parts, that we are not often justified in resorting to an operation of some danger for the doubtful chance of relieving this one of the many ailments under which the patient suffers.

\section{ON OVARIOTOMY.}

\section{BY JOHN CROUCH, Esa., M.R.C.S.,}

GUREXON TO THE BRUTON HOSTITAL, FORMBRLX HOUSB-BURGBON TO WINCHXSTEB HORPITAX

(Read at the Quarterly Mceting of the Bath and Bristol Branch of the Provincial Medical and Surgical Association, Sept. 27th 1849.)

Mr. President, - Having lately performed with success an operation for the extirpation of a multilocular ovarian cyst, an account of which has appeared in the Journal of our Parent Association, I will venture, with your permission (this being the first case that has occurred in the western part of Englaud,) to offer a few remarks in justification of so dangerous a proceeding.

In doing this, I will not attempt to advance any new facts on the subject, but endeavour to excite a 
discussion as to whether the art of medicine can suggest any remedy which would preclude the necessity of resorting to so fearful an expedient as " ovariotomy."

Every one present, I think, will accede to the opinion of Mr. Safford Lee, who says that "the operation is a defect in the art of surgery, and that the knife should be avoided in all cases that it is possible; and that surgeon (he continues) will be esteemed the greatest benefactor to society and the world at large, who would suggest some means by which the disease could be cured without reverting to "ovariotomy.'" The question I would ask then, is, do we possess any medical remedy which can be depended upon for the cure of ovarian dropsy?

Dr. Hunter says that "ovarian dropsy is an incurable disease, and that the patient will have the best chance of living longest under it who does the least to get rid of it." Dr. Elliotson remarks,- " If any medicine does good in these cases it is iodine;" but although he has seen " some cases diminished, and some apparently cured," by this remedy, he agrees with Dr. Ashwell, and other eminent physicians, that no medicine can be relied on in this troublesome disease.

Dr. Watson, in the last edition of the "Principles and Practice of Physic," published so recently as 1848 , observes,- " My position, as physician to a hospital, has brought under my notice many cases of ovarian swelling, at a very early period of its development. I have treated such cases assiduously with the remedies of chronic inflammation, frequent topical bleedings, and the use of mercury, till the gums were affected; with the remedies of ordinary dropsy, diuretics, and drastic purgatives; and with remedies accounted specific, the Liquor Potassæ, and the various preparations of iodine; and I must honestly confess to you that I am unable to reckon one single instance of success."

Secondly, I would appeal to the members of this Association as to whether the system of " compression," recommended and tried by Dr. Hamilton, of Edinburgh, and Mr. Brown, of London, holds out any reasonable promise of cure? In the opinion of many who are competent to decide, this remedy is considered an entire failure, or at best only capable of preventing the rapid growth of ovarian tumours.

It would indeed be most gratifying could it be proved, that " pressure," or " iodine," or " diuretics," or any other medicine could avail, in the case of a multilocular cyst.

Thirdly, I would ask, what dependence can be placed on "Paracentesis Abdominis" as a remedy in ovarian dropsy? Dr. Blundell, a most eminent authority, says,_- "Make the best of it, and tapping, after all, is an unsatisfactory sort of remedy; dangerous in scirrho-dropsy; of partial relief in dropsy of many cysts ; of no effect where the cystic material is viscid; obnoxious to inflammations, adhesions, suppurations, exhaustions, repetitions, and death, even in cases the most favourable; and the more $I$ have seen of the operation (continues the doctor) the more I have felt inclined to whisper to myself, when the surgeon has taken up the instrument, I wish I could do something better."
It appears also, that the operation of " tapping," which has hitherto been considered the best mode of palliating the disease, is a more dangerous remedy than was formerly supposed. Out of forty-six cases of ovarian dropsy, collected by Mr. Southam and Mr. Lee, twenty died after the first tapping, sixteen within one month after the operation, and ten of these sixteen, or one half of the whole number, died in seven days after the evacuation of the cyst. "Paracentesis abdominis" never effects a cure, except in the case of a unilocular or simple cyst. It is almost as dangerous an operation as ovariotomy, and seldom gives more than temporary relief. This may be considered the most potent argument in favour of ovariotomy.

Another strong reason for seeking a more efficient remedy than "tapping" is, the early mortality of ovarian disease. Mr. Lee states that "he has seen a small ovarian cyst progress so rapidly in a fortnight as to acquire a large size, obstruct the breathing, and severely impede the vital functions." Of fifty cases which came under the notice of Dr. Frederick Bird, four died within one year from the commencement of the abdominal enlargement, twelve within two years, twelve within three years, ten within four years, and all the others within ten years.

Several other surgical operations on the cyst itself have been suggested and performed. Portions of the cyst have been excised, setons have been passed through the walls of the sac to produce inflammation and adhesion, moreover the cyst has been injected with irritating fluids; but all these plans, as they are seldom attended with success, have been pretty generally discarded from modern practice.

Lastly, with regard to the operation of ovariotomy. I am aware that we have high authority against its performance. Sir Charles Bell, Dr. Hunter, Mr. Lawrence, Dr. Seymour, and the late Mr. Liston, have all recorded their opinion that the operation is unjustifiable.

On the side of those who sanction the operation, Dr. Blundell, Dr. Clay, and Dr. Frederick Bird, may be justly considered a host in themselves, because the first of these gentlemen has spent a long life in a constant attention to the subject, and, as early as 1822 , predicted that the operation would, some day, come into general use; the second has saved the lives of twenty-three patients by this glorious triumph of modern surgery; the last has performed the operation seven times with unvaried success.

In addition to this it appears, from a table I have drawn out, that in England alone twenty-three medical men, whose names have been published, have performed the operation with various success, and five of these are London hospital surgeons.

The number of cases of ovariotomy performed by these twenty-three operators is seventy-three and thirtytwo of these by Dr. Clay. Of the seventy-three cases forty-nine were successful, and twenty-four fatal, causing a mortality of one in every three cases. This great mortality has arisen, perhaps, from a bad selection of cases for the operation, and from the imperfect way in 
which the vessels of the pedicle have been secured, as by far the more frequent causes of death are hæmorrhage and peritonitis, the latter being the consequence of extensive arlhesions.

In making the above calculations I exclude those instances of gastrotomy in which no tumour was removed, because these errors are not so likely to recur when the diagnosis of ovarian tumours becomes more accurate. It is clear that skill alone in the operation is not the only requisite necessary for success, since, of the five London hospital surgeons above alluded to, viz., Mr. Bransby Cooper, the late Mr. Aston Key, Mr. Solly, Mr. Benjamin Phillips, and Mr. Cæsar Hawkins, the latter gentleman is the only one who has succeeded. It is also absolutely necessary that the case should be well suited to the operation, the patient of a good constitution, and of previously healthy habits, and that the most rigid attention should be paid to the temperature of the room, as well as to the after-treatment.

It is useless for any one to attempt to decide which is the best of the three operations proposed, the "large," section.

TABLE

Shewing the result of seventy-three cases of Ovariotomy, which have been performed in England by operators whose names have been published.

\begin{tabular}{|c|c|c|c|c|c|c|c|}
\hline OpERATORs. & & $\begin{array}{c}\text { Cyst removed } \\
\text { entire by "Nfajor } \\
\text { Operation." }\end{array}$ & $\begin{array}{c}\text { Cyst removed by } \\
\text { large incision and } \\
\text { puncture. }\end{array}$ & $\begin{array}{c}\text { Cyst removed } \\
\text { by median section } \\
\text { and puncture. }\end{array}$ & $\begin{array}{l}\text { Crst removed } \\
\text { by “Minor } \\
\text { Operation." }\end{array}$ & Fataz. & SUCCEssfot. \\
\hline Dr. Clay & ... & 26 & 6 & $\cdots$ & $\cdots$ & 12 & 20 \\
\hline Mr. Walne $\quad \ldots \quad$.. & & 4 & $\cdots$ & $\cdots$ & ... & 1 & 3 \\
\hline Mr. Jeaffreson & .. & $\cdots$ & $\cdots$ & 1 & 1 & 1 & 1 \\
\hline Mr. King $\quad \ldots \quad$.. & .. & $\cdots$ & $\cdots$ & $\cdots$ & 1 & $\cdots$ & 1 \\
\hline Mr. West $\quad \ldots \quad$.. & .• & $\cdots$ & $\cdots$ & $\cdots$ & 3 & 1 & 2 \\
\hline Mr. B. Phillips &. & $\cdots$ & $\cdots$ & $\cdots$ & 1 & 1 & $\cdots$ \\
\hline Mr. Crisp $\quad \ldots \quad \ldots$ & .. & $\cdots$ & $\cdots$ & $\cdots$ & 1 & $\cdots$ & 1 \\
\hline Mr. Southam & & $\cdots$ & 2 & $\cdots$ & 1 & 1 & 2 \\
\hline Mr. Morris ... ... & .. & $\cdots$ & 1 & $\cdots$ & $\cdots$ & $\cdots$ & 1 \\
\hline Dr. F. Bird $\ldots$ & .• & $\cdots$ & $\cdots$ & $\tau$ & $\cdots$ & $\cdots$ & 7 \\
\hline Mr. Heath $\quad \ldots \quad$.. & .. & $\cdots$ & $\mathbf{1}$ & $\cdots$ & $\cdots$ & 1 & $\cdots$ \\
\hline Mr. Lane $\quad \ldots \quad$.. & .. & $\cdots$ & 4 & 1 & 1 & 1 & $\mathbf{5}$ \\
\hline Mr. Aston Key .. & & $\cdots$ & I & $\cdots$ & $\cdots$ & 1 & $\cdots$ \\
\hline Mr. B. Cooper .. & .. & $\cdots$ & 1 & $\cdots$ & $\cdots$ & 1 & $\cdots$ \\
\hline Mr. Greenhow .. & 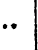 & $\cdots$ & 1 & $\cdots$ & $\cdots$ & 1 & $\cdots$ \\
\hline Mr. W. B. Page .. & $\cdots$ & $\cdots$ & $\therefore$ & 1 & $\cdots$ & $\cdots$ & 1 \\
\hline Mr. J. Dickin $\quad$.. & .. & $\cdots$ & 1 & $\cdots$ & $\cdots$ & $\cdots$ & 1 \\
\hline 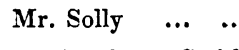 & & $\cdots$ & $\cdots$ & 1 & $\cdots$ & 1 & $\cdots$ \\
\hline Dr. Protheroe Smitl & & $\cdots$ & 1 & $\cdots$ & $\cdots$ & 1 & $\cdots$ \\
\hline Mr. H. E. Burd .. & & $\cdots$ & 1 & $\cdots$ & $\cdots$ & $\cdots$ & 1 \\
\hline Mr. Cæsar Hawkin & & $\cdots$ & $\cdots$ & $\cdots$ & 1 & $\cdots$ & 1 \\
\hline Mr. Elrington $\quad .$. & & $\cdots$ & 1 & $\cdots$ & $\cdots$ & $\cdots$ & 1 \\
\hline Mr. Crouch ... .. & $\cdots$ & $\cdots$ & 1 & $\cdots$ & $\cdots$ & $\cdots$ & 1 \\
\hline & & 30 & 22 & 11 & 10 & 24 & 49 \\
\hline
\end{tabular}

the "median," or the "minor," as neither of them would apply to every case, and each has its own peculiar advantages according to the size of the solid part of the tumour to be removed.

In conclusion, I would venture to assert, that not only is the operation legitimate and justifiable, provided an appropriate case is chosen, and the diagnosis made clear, but that, if other means fail, in the words of Mr. Lee, " the surgeon is bound to give to his patient the last aid of his art, and remove a tumour, which if allowed to remain tends to destruction."

Allow me to add, Sir, that I will offer for the inspection of the gentlemen present the ovarian cyst that was taken from my patient, and I think it will be infeired, from its size and the number of separate cells it contains, that there was little hope that any means, short of extirpation, could have effected a cure ; and as the greater number of these sacs contained a fluid which could not be let out with the trocar, the only way of removing the tumour was by a large abdominal 